\title{
MAS O QUE EU SEI? O MOVIMENTO DA APRENDIZAGEM DA ESCRITA ACADÊMICA A PARTIR DA ANÁLISE TEXTUAL DISCURSIVA
}

\section{BUT WHAT DO I KNOW? THE MOVEMENT OF LEARNING IN ACADEMIC WRITING FROM DISCURSIVE TEXTUAL ANALYSIS}

Roberta Chiesa Bartelmebs ${ }^{1}$

\begin{abstract}
Resumo: Os primeiros passos em uma nova atividade sempre trazem um misto de sentimentos. Medo, ansiedade, expectativas. Não é diferente da atividade acadêmica. Quando ingressamos na graduação ou na pós-graduação, todas as disciplinas e atividades se constituem novidades em nosso repertório comportamental. Neste artigo, apresento aos leitores minha visão enquanto professora da área de Ensino, e pesquisadora no paradigma da pesquisa qualitativa, o quanto aprender uma metodologia de análise pode ser desafiadora. Esse material tem dois objetivos principais: Apresentar uma metodologia de práticas com a ATD que faço uso para ensinar esta metodologia aos alunos, e, apresentar minhas reflexões acerca da importância de, desde a graduação, os alunos terem contato com metodologias de análise estruturadas.
\end{abstract}

Palavras-Chave: Análise Textual Discursiva; Escrita; Aprendizagem.

\begin{abstract}
The first steps in a new activity always bring mixed feelings. Fear, anxiety, expectation. It is not different from academic activities. When students start undergraduate and graduate courses, all disciplines and activities are new to their behavioral repertoire. This paper introduces the author's view as a teacher in the field of teaching and as a researcher in the qualitative research paradigm, related to how challenging learning an analytical methodology can be. This paper has two main objectives, i. e., it aims at introducing the methodology of practices with the Discursive Textual Analysis (DTA) that the author applies to teach it to her students and at exposing the author's reflections on the importance of enabling students to have contact with structured analytical methodologies since the beginning of their undergraduate courses.
\end{abstract}

Keywords: Discursive Textual Analysis (DTA); Writing; Learning.

\section{Os meus primeiros passos na Análise Textual Discursiva ATD}

Este é um ensaio acerca da Análise Textual Discursiva (ATD) no processo de aprendizagem sobre pesquisa qualitativa. Peço licença ao leitor para fazer um breve relato acerca de como iniciei minha trajetória na pesquisa qualitativa e sua relação com a ATD. Em 2009 conheci pessoalmente o professor Roque Moraes. Ainda na licenciatura, me encantei com seu texto: "É possível ser construtivista no ensino de ciências?"”. Eis que,

\footnotetext{
${ }^{1}$ Doutora em Ensino de Ciências e Matemática pela Pontifícia Universidade Católica do Rio Grande do Sul (PUCRS). Professora e pesquisadora na Universidade Federal do Paraná - Setor Palotina e no Programa de Pós-Graduação em Educação em Ciências, Educação Matemática e Tecnologias Educativas (PPGECEMTE). Palotina, Paraná, Brasil. E-mail: roberta.bartelmebs@ufpr.br

2 MORAES, R. É possível ser construtivista no Ensino de Ciências? In: MORAES, R. (org.). Construtivismo e ensino de ciências: reflexões epistemológicas e metodológicas. 3. ed. Porto Alegre: EDIPUCRS, 2008. p. 103-129.
} 
alguns anos depois, com extrema empatia e acolhida, ele me recebe para avaliar minha ideia de projeto de pesquisa para o mestrado.

A partir desse dia, entrei num mundo totalmente novo. Embora tenha feito inúmeras leituras na graduação, nunca havia tido um estudo mais profundo sobre a pesquisa qualitativa.

Em 2010, iniciei o primeiro texto sobre meu tema de pesquisa: Educação em Astronomia. A primeira orientação recebida foi: "Escreva tudo o que vier à sua mente sobre Educação em Astronomia". Lembro de pensar: "Mas o que eu sei? Não terei muitas ideias para colocar nesse arquivo em branco do word...". Tenho ainda todos os arquivos desse primeiro exercício de ATD que realizei. O arquivo contendo as unidades iniciais do texto se intitulava "minhas ideias sobre Astronomia". Ao mesmo tempo que escrevia meu arquivo, o professor Roque escrevia o dele. Depois nós trocamos os arquivos e cada um fez novas unidades sobre as unidades do outro. Eu chamo esse processo de "ATD às avessas”. Isso porque ao invés de utilizá-la para analisar um texto pronto, ou seja, um corpus de análise, nós a utilizamos para construir um!

E é esse processo de construção de texto a partir da ATD que eu desejo explorar neste artigo. Nos próximos itens, vou apresentar todos os passos seguidos e nossa fundamentação teórica para tal. Bem como, ilustrarei com exemplos de minha própria prática, como é possível tornar o processo de escrita, na graduação, mais criativo e autoral a partir da ATD às avessas.

\section{Breve resumo dos passos da ATD}

A ATD é uma metodologia de cunho hermenêutico-fenomenológico. Como descrevem os autores dessa proposta metodológica: “A análise textual discursiva corresponde a uma metodologia de análise de dados e informações de natureza qualitativa com a finalidade de produzir novas compreensões sobre fenômenos e discursos" (MOARES; GALIAZZI, 2007, p. 7). Ou seja, a ATD propicia ao pesquisador ferramentas de análise de discursos e fenômenos, através de uma metodologia sistemática, mas não rígida, que permite e de certa forma exige a criatividade do pesquisador nos seus diferentes momentos de trabalho analítico.

A ATD aposta na escrita como principal ferramenta de trabalho do pesquisador, assim como a classificação de seu material empírico, unitarização e categorização, feita 
sempre com o suporte recursivo da escrita e da reescrita. De modo bem geral, podemos dizer que são três passos principais que compõe esta metodologia.

O primeiro passo é a unitarização, ou seja, a divisão do corpus de análise em pequenos trechos ou unidades de significado. O segundo passo é a classificação inicial em categorias iniciais, isto é, grande número de categorias nas quais se reúnem as unidades que se aproximam pelo seu sentido e significado. Categorização Intermediária e Final, que tem por objetivo reunir por aproximações as categorias anteriores. A cada nova classificação em categorias, argumentos de justificativa são produzidos, validando a existência de todas as categorias através de suas unidades. Por fim, o último passo é a construção do metatexto, isto é, a partir da categorização a elaboração da construção textual final, onde a tese e as hipóteses da pesquisa são colocadas à prova pelos argumentos produzidos no decorrer do processo de categorização.

Com a ATD, o pesquisador se assume autor daquilo que escreve, se assume "efetivamente sujeito" da sua pesquisa e movimenta-se no sentido de reconstruir suas próprias teorias e seus próprios conhecimentos, isto por quê: "O processo de análise consiste em um constante ir-e-vir, agrupar e desagrupar, construir e desconstruir. $\mathrm{O}$ processo é de constantes retomadas, avaliando-se com frequência tudo que já foi realizado para refazê-lo ou melhorá-lo" (MORAES; GALIAZZI, 2007, p.187).

Nesse sentido, o processo recursivo da escrita pode potencializar o olhar do pesquisador sobre seus dados, abrindo a possibilidade de revisitar as categorias elaboradas tanto a priori quanto utilizar-se das categorias que emergirem no decorrer da análise.

Segundo Moraes e Galiazzi (2007, p. 29):

Categorias constituem conceitos abrangentes que possibilitam compreender os fenômenos, que precisam ser construídos pelo pesquisador. Da mesma forma como há muitos sentidos em um texto, sempre é possível construir vários conjuntos de categorias a partir de um mesmo conjunto de informações.

Os sentidos construídos pelas categorias não são "dados prontos", é preciso um grande esforço “construtivo". Nesse sentido, é necessário criar coerência entre os elementos das categorias, elaborando argumentos que solidifiquem a compreensão do todo pelas partes, e das partes pelo todo. Isso porque, segundo Moraes e Galiazzi (2007, p. 30): "Em vez de defesa com números, característica de abordagens quantitativas, nas abordagens qualitativas é preciso fazê-la com argumentos”. Esses argumentos culminam, na ATD em metatextos, que se constituem em "descrição e interpretação" que representam o conjunto de argumentos sobre o que é investigado. 
O processo de ATD permite construir aprendizagens sobre a própria aprendizagem da pesquisa e da escrita. Como definem Moraes e Galiazzi (2007, p.231):

Entender as aprendizagens como reconstruções do já anteriormente construído implica compreendê-las num sentido que se aproxima do funcionamento dos próprios processos vitais, auto organizados e emergentes, em que continuamente novas formas de vida são gestadas em processo autopoiéticos capazes de garantirem a sobrevivência tanto dos indivíduos quanto dos grupos sociais.

Segundo ainda os autores, não deixa de ser um constante "ressurgir da Fênix" o processo de desconstrução, construção e reconstrução implicados na ATD. E ainda, conforme apontam Sousa e Galiazzi (2018), a ATD é uma metodologia muito utilizada com o sentido de possibilitar a compreensão de algum fenômeno, sendo que este processo pode se formar entre um "quebra cabeças", cujas peças já estão pré-definidas, ou ainda, como um "mosaico", que nas palavras dos autores pode se tratar de:

\footnotetext{
[...] um movimento de mudança da compreensão inicial da pesquisa nos procedimentos da metodologia em que o pesquisador faz modificações de acordo com seu material empírico e no encontro com teorias desconhecidas antes da pesquisa ou teorias assumidas a priori, mas que foram ampliadas no decorrer da pesquisa (SOUSA; GALIAZZI, 2018, p. 808).
}

Em todas as etapas da ATD, estão implicadas as teorias pessoais dos pesquisadores, suas crenças epistemológicas e metodológicas, incidindo tanto na análise quanto nos resultados. Dessa forma, explicitamos que, no nosso processo de utilização da ATD, partimos de teorias a priori concebidas durante o planejamento do curso piloto, que culminaram na construção de algumas categorias a priori. Mas também submetemos nossos dados a natureza fenomenológica da ATD, visualizando assim categorias emergentes a partir da análise das transcrições feitas.

\section{Vida acadêmica: Sonhou ou pesadelo?}

Antes de falar acerca da escrita a partir da ATD, gostaria de refletir um pouco sobre o que nos move aos processos de escrita na academia. O que é pesquisar? Por que escrevemos artigos, monografias, dissertações e teses? Juntamente com o prof ${ }^{\circ}$ Dr Roque Moraes, escrevemos nos cadernos de metodologia da pesquisa, enquanto convidados a refletir sobre metodologia qualitativa para alunos de um Curso de Pedagogia de uma Universidade Federal do Sul Gaúcho:

Pesquisar, como bem sabemos, é mais do que levantar informações. Constituise, principalmente, como forma de sistematizar os dados e interpretá-los. Sendo assim, a partir do momento em que os dados são coletados, sistematizados e anexados ao trabalho, é hora de nos perguntarmos: qual 
caminho metodológico de análise a seguir? (MORAES; BARTELMEBS, 2013, p. 29).

Nas ciências humanas o processo de pesquisa está intimamente ligado ao processo de escrita. E o que é escrever? Uma definição que penso que tenha um grande valor para nossa argumentação neste artigo é a de Taís Schmitz, inspirada em Mario Osório Marques: "[...] o ato de escrever, é uma tessitura de significados constituídos no entrelaçamento físico de vestígios, é a fixação, em um suporte material, da obra humana na história" (2010, p. 144).

Escrever é deixar sua marca na história. Mas embora poético, esse fazer não é tão romântico na prática. Existem estudos mostrando a relação entre o stress e a ansiedade vinculados a vida acadêmica, ou seja, estritamente ligados à atividade da escrita acadêmica. A linguagem escrita é uma valiosa ferramenta de transmissão de ideias e conhecimentos. O cérebro humano se moldou para ser capaz de representar o mundo através da linguagem escrita, e da leitura a partir da primeira revolução cognitiva da humanidade (YUVAL, 2015). E na verdade, estudos como os de Dehaene (2013) apontam que aprender a ler e a escrever realmente modifica o cérebro humano. Podemos dizer que hoje, a partir do advento da escrita acadêmica, essa linguagem também sofreu modificações, assim como além de sermos alfabetizados (ou letrados), precisamos também aprender a ler e a escrever dentro do estilo acadêmico.

E muitas vezes, nesse momento de novas aprendizagens, que é caracterizado pela graduação e pós-graduação, podemos nos deparar com desafios "adicionais".

\footnotetext{
No transcurso da vida, em determinadas ocasiões, as pressões biopsicossociais são responsáveis por desequilíbrios na homeostase do indivíduo, prejudicando seu desempenho nas mais variadas circunstâncias. Essas pressões geradoras de estresse são vivenciadas em diversas oportunidades tanto na vida pessoal, social, profissional e, não menos diferente, durante a trajetória acadêmica. No ambiente acadêmico, a resolução de problemas se faz imperiosa. Além disso, é sabido que os estudantes universitários passam por momentos de mudança, desenvolvimento, frustração, crescimento, temores e angústias. Assim, o ambiente que contribuiria na edificação do conhecimento e ser a base para as suas experiências de formação profissional se torna, por vezes, o desencadeador de distúrbios patológicos, quando ocorre uma exacerbação da problemática do estresse acadêmico nos estudantes (MONTEIRO; FREITAS; RIBEIRO, 2007, p. 67).
}

Nesse extrato do trabalho de Monteiro, Freitas e Ribeiro, percebemos algumas nuances da vida acadêmica, especialmente para o jovem aluno recém chegado dos portões escolares. Existem dificuldades inerentes as mudanças naturais que ocorrem na vida de quem ingressa em uma Universidade, e isso não é algo banal. E embora faça parte do 
crescimento individual e coletivo, é um ponto ainda a ser mais bem compreendido pelos docentes do nível superior.

\begin{abstract}
No contexto acadêmico, ao ingressar em uma instituição universitária, podese dizer que o estudante enfrenta desafios como aquisições de novas responsabilidades, sobrecarga de trabalho e falta de tempo. Sob o prisma da análise do comportamento, essas contingências podem produzir respostas de medo e ansiedade, capazes de repercutir negativamente na capacidade adaptativa, provocando prejuízos funcionais ou consequências na qualidade de vida, nas relações sociais e mesmo no desempenho acadêmico. Certos autores apontam que o estresse pode prejudicar o desempenho universitário por meio da diminuição da atenção, da concentração e da perda de habilidades para tomada de decisões (MORETTI; HÜBNER, 2017, s/p).
\end{abstract}

Corroborando com o dito anteriormente, mudanças ambientais geram mudanças comportamentais, e nesse sentido podem gerar problemas de ansiedade, que normalmente levam a uma perda da qualidade de vida da pessoa. Isso afeta diretamente o desempenho acadêmico do sujeito.

Em uma recente pesquisa publicada na Revista Nature, Li et al., (2020), apontam que, a prevalência de depressão entre alunos chineses nas universidades é bastante alta, mas o artigo relata uma outra faceta do problema: as questões socioeconômicas envolvidas na vida do graduando. Resguardadas as diferenças culturais, sociais e econômicas entre China e Brasil, há uma forte relação entre o tamanho de nossos países e sua constituição socioeconômica. Assim como na China, muitos jovens brasileiros precisam se deslocar para grandes centros para frequentarem o Ensino Superior. Isso muda completamente suas vidas, e muitas vezes os encarrega da responsabilidade de garantir sua sobrevivência durante os anos de graduação.

E na pós graduação o problema parece se agravar. Segundo dados publicados em uma reportagem do Grupo A, uma pesquisa internacional do ano de 2018 revelou que "mestrandos e doutorandos têm seis vezes mais chance de sofrer ansiedade e depressão do que a população em geral" (CRUZ, 2018, s/p.).

Enfatizando essa situação, a pesquisa de Faro (2013) já apontava para sobrecarga da pós graduação, para alunos e professores, em relação a produção acadêmica. Segundo as pesquisas realizadas pelo autor: "os estudantes se percebem em meio à incompatibilidade entre a vida fora da universidade e a lógica do publicar ou perecer" (p. 52). Na escala de estressores encontrados pelo autor, grande parte das preocupações que invadem a vida dos pós-graduandos diz respeito ao seu desempenho nas disciplinas, na banca, nos eventos e na realização de seu trabalho de pesquisa. 
A pesquisa na área da Educação ou Ensino é baseada na escrita. Mas se nossos alunos desde a graduação até a pós-graduação estão cada vez mais comprometidos em sua saúde física e mental, como podemos produzir com qualidade? Iniciar com essa reflexão pode nos ajudar a compreender que os nossos alunos são sujeitos no mundo. $\mathrm{E}$ nesse sentido vivem suas angústias, prazeres e medos como qualquer um de nós. Porém, há agravantes que podem afastá-los de suas carreiras e até mesmo impedi-los de serem plenamente realizados.

Como professora e pesquisadora, me pergunto: como podemos evitar esse mal estar? Como podemos produzir academicamente com saúde física e mental? E um dos caminhos que tracei, e que venho mostrar neste artigo, é a utilização da ATD às avessas. A ideia, como dito no início deste texto, surge da experiência pessoal na escrita de um projeto de mestrado. E perdurou por toda a dissertação e vida acadêmica da autora. Mas como é essa tal de ATD às avessas? O que a constitui? O que a fundamenta?

\title{
4 Dando corpo a ATD às avessas: Construção de um texto a partir das ideias do autor
}

A ATD às avessas tem o mesmo fundamento da ATD:

\begin{abstract}
Em outras palavras, a ATD é uma metodologia QUALITATIVA que se preocupa com a análise dos dados coletados e tem por finalidade PRODUZIR NOVAS COMPREENSÃO sobre aquilo que estamos pesquisando. A ATD se preocupa, ainda, com o processo de autoria de quem escreve um trabalho científico. Para tanto, sua principal ferramenta é a escrita (MORAES; BARTELMEBS, 2013, p. 30, grifos dos autores).
\end{abstract}

A ideia de autoria na ATD é muito forte. Não se trata de um recorte de palavras e uma costura enviesada para produzir um texto. Se trata de uma imersão completa, íntima com o texto. É uma desconstrução organizada e sistemática com o propósito de possibilitar que novas ideias surjam. Basicamente isso se dá no primeiro passo, a unitarização.

Sobre a unitarização, na ATD, a partir de um texto pronto:

O momento da unitarização é um movimento desconstrutivo. Consiste numa explosão de idéias (sic), uma imersão no fenômeno investigado, por meio do recorte e discriminação de elementos de base, tendo sempre como ponto de partida os textos constituintes do "corpus" (MORAES; GALIAZZI, 2007, p.49, grifo dos autores).

Este passo pode também ser feito a partir de uma folha em branco. Neste caso, as pequenas unidades serão produzidas pelo(s) autor(es) do texto. No entanto, ninguém escreve um texto a partir do "nada". A rigor, podemos até dizer que o nada não existe em 
termos de ideias, pois, sempre haverá algo anterior de nossas vivências e crenças. A grande questão é saber qual é a sua pergunta. Como bem colocou o mestre pernambucano da Educação brasileira: "Perguntar e responder são caminhos construtivos da curiosidade. É necessário estar sempre à espera de que um novo conhecimento surja, superando outro que, já tendo sido novo, envelheceu" (FREIRE, 1995, p. 19).

Um texto, assim como qualquer pesquisa científica, começa sempre com alguma pergunta. Algo insatisfatório, alguma coisa que ainda não se encaixou muito bem... é o espaço de surgimento do novo. Mas esse novo é também herdeiro do nosso próprio passado. Como aponta Creswell:

A forma como escrevemos é um reflexo da nossa própria interpretação, baseada na política cultural, social, de gênero, classe e pessoal que trazemos para a pesquisa. Toda escrita está "posicionada" e inserida em uma determinada postura. Todos os pesquisadores moldam a sua escrita, e os pesquisadores qualitativos precisam aceitar essa interpretação e manterem-se abertos quanto a isso em seus escritos (CRESWELL, 2014, p. 172).

É a partir destas reflexões teóricas, políticas e filosóficas acerca do ato de escrever na pesquisa qualitativa que "inicio" meus alunos da mesma forma como fui iniciada na escrita: Com o uso da ATD às avessas. A primeira tarefa que lhes dou é escrever o que vem a sua mente acerca do tema de investigação de sua pesquisa. Para Figueiredo:

Construir parágrafos é organizar e desenvolver ideias, umas ligadas às outras. Organizar e desenvolver ideias é difícil; por isso, requer um método que facilite o trabalho do escritor. Esse método depende da cultura e do modo de pensar de cada povo". Para este autor, tudo começa com o parágrafo (FIGUEIREDO, 1999, s/p.).

Utilizo sua ideia essencial, mas adapto a algo menor: a frase. O primeiro passo é ter em mãos um editor de texto, ou um suporte no qual você possa registrar suas ideias. Assemelhando-se a uma "tempestade de ideias", neste momento o autor vai permitir-se falar daquilo que lhe interessa. Seja seu tema de pesquisa, seja o tema de um artigo de disciplina, a primeira coisa é colocar no papel (ou na tela) todas as ideias que lhe vêm à mente sobre o tema.

A organização é a mesma da unitarização. Cada frase elaborada ganha um código e um título. O próximo movimento, segue os passos da ATD: categorização inicial, intermediária e final. Neste entremeio, realizamos também a unitarização de ideias de autores que trabalham com a nossa temática, a partir de fichamentos de leituras. Isso nos permite "mergulhar" em discursos próximos aos nossos, como apontam Moraes e Galiazzi (2007), no $5^{\circ}$ capítulo da obra, intitulado: Mergulhos dirscursivos: análise textual 
discursiva entendida como processo integrado de aprender, comunicar e interferir em discursos.

Ou seja, com a ATD é possível aprender algo novo, no caso da ATD às avessas, talvez seja a aprendizagem daquilo que o autor sabe, mas ainda não está explicito. Mas para além disso, ela permite que se comunique essa aprendizagem e ao mesmo tempo que se façam reflexões teóricas com outros autores. Como apontam Moraes e Galiazzi (2007):

\begin{abstract}
Sintetizando, podemos afirmar que a análise textual discursiva é um processo integrado de análise e de síntese que se propõe a fazer uma leitura rigorosa e aprofundada de conjuntos de materiais textuais, com o objetivo de descrevêlos e interpretá-los no sentido de atingir uma compreensão mais complexa dos fenômenos e dos discursos a partir dos quais foram produzidos (MORAES, GALIAZZI, 2007, p. 114).
\end{abstract}

Posterior a essa primeira categorização, realizamos o movimento de escrita de argumentos para cada uma das categoriais iniciais. Isso futuramente no texto pode ser o início da escrita de seus parágrafos. Assim o texto nasce aos poucos.

Um próximo passo é a categorização intermediária, isto é, unir as categorias iniciais por proximidades, dando-lhes novo título e construindo novos metatextos para cada uma delas, agora mais abrangentes. Como apontam Moraes e Galiazzi (2007):
A escrita propriamente dita de um texto é encaminhada a partir da categorização. Pode ser iniciada pela escrita de parágrafos com base nas categorias menos abrangentes construídas, seguida de um encadeamento cada vez mais consistente dos parágrafos entre si" (MORAES, GALIAZZI, 2007, p. 207).

Retomando a ideia da escrita pelo parágrafo (FIGUEIREDO, 1999), apontada anteriormente, podemos dizer que a construção do texto já se inicia com a primeira categorização, isto porque: "É importante salientar que nã se trata simplesmente de costurar as ideias das categoriais, mas de expressar seu sentido dentro da perspectiva do pesquisador. É o momento de assumir-se como autor" (MORAES; GALIAZZI, 2007, p. 207).

Este momento é bastante desafiador. Geralmente os alunos facilmente conseguem elaborar suas unidades na ATD às avessas, criando um bom grupo delas com suas ideias iniciais. No entanto, iniciar a categorização e elaborar argumentos para elas passa a desafiá-los num nível diferente.

Certamente esse processo de torna cada vez mais complexo e exige abstrações mais refinadas (PIAGET, 1995) acerca do que está dito no texto. É preciso aprender não somente a ter um olhar metacognitivo sobre sua própria escrita, como, também, a tornarse autor com os outros. Conforme apontam Moraes e Galiazzi: 
Validamos nossos textos ancorado-os em teóricos e especialistas nos temas sobre os quis trabalhamos. Escrever um texto é estabelecer espaços de diálogo com uma comunidade de especialistas, passndo o autor de uma periferia para posições mais centrais assumindo cada vez mais o papel de autoridade (MORAES; GALIAZZI, 2007, p. 210).

Sendo assim, o processo de escrita avança de modo autoral, sem aquela ansiedade do cursor piscando em uma tela preta. Tudo nasce das ideias do(s) autor(es), e a partir delas, o emaranhado complexo de construção de argumentos surge. E é a partir dele que o texto final se completa. Muitos alunos ficam surpresos em perceberem que o texto vai se estruturando já desde os primeiros passos da ATD. O sofrimento da escrita em uma tela em branco deixa de existir, pois, não há mais uma tela em branco. O ponto de partida são suas ideias, que depois confrontam-se com a dos autores estudados sobre o tema, e por fim, refina-se seus argumentos a ponto de tornar-se um metatexto robusto e consistente.

\section{Considerações finais}

Como vimos, a vida acadêmica pode ser bastante desafiadora. Além disso, o processo de escrita está essencialmente ligado ao processo de pesquisa e busca de novos significados na pesquisa qualitativa. Nesse sentido, aprender a construir um texto coerente, consistente e autoral é um enorme desafio. Porém, com a utilização da "técnica" adequada, esse processo pode ser não só prazeroso como também se tornar parte da rotina de trabalho de um pesquisador.

A imersão aos dados que a ATD proporciona possibilita uma compreensão profunda dos significados ditos e não ditos no texto de um pesquisador. Partir das suas ideias é também se tornar conhecedor de suas crenças e vivências. E todo pesquisador tem muito a ganhar com essa possibilidade de emergir no seu próprio texto. Assim, quando ouço, "Mas o que eu sei?", digo que geralmente sabemos muito mais do que pensamos, basta aprender a explicitar esse saber. E com a ATD não apenas explicitamos isso, como, também, comunicamos e aprendemos a autoria.

\section{Referências}

CRESWELL, J. W. Investigação qualitativa e projeto de pesquisa. 3. ed. Porto Alegre: ArtMed, 2014.

CRUZ, F. la. Por que depressão e ansiedade afetam cada vez mais universitários, 2018. Disponível em: https://desafiosdaeducacao.grupoa.com.br/ansiedade-e-depressao-nauniversidade/. Acesso em: out. 2020. 
DEHAENE, S. A aprendizagem da leitura modifica as redes corticais da visão e da linguagem verbal. Letras de Hoje, Porto Alegre, v. 48, v. 1, p. 148-152, jan./mar. 2013.

FARO, A. Estresse e estressores na Pós-Graduação: Estudo com Mestrandos e Doutorandos no Brasil. Psicologia: Teoria e Pesquisa, Brasília, v. 19, n. 1, p. 51-60, jan./mar. 2013.

FIGUEIREDO, L. C. A redação pelo parágrafo. Brasília: Editora Universidade de Brasília, 1999.

FREIRE, P. A sombra desta mangueira. São Paulo: Editora olho d'água, 1995.

LI, L. et al. Prevalence of depression and its relationship with quality of life among university students in Macau, Hong Kong and mainland China. NATURE, Scientific Reports, London, n. 10, p. 01-08, September. (2020). https://doi.org/10.1038/s41598-020-72458-w. Acesso em: out. 2020.

MONTEIRO, C. F. de S.; FREITAS, J. F. de M.; RIBEIRO, A. A. P. Estress no cotidiano acadêmico: o olhar dos alunos de enfermagem da Universidade Federal do Piauí. Escola Anna Nery Revista de Enfermagem, Rio de Janeiro, v. 11, n. 1, p. 66 - 72, mar. 2007. Disponível em: https://www.scielo.br/pdf/ean/v11n1/v11n1a09.pdf. Acesso em: out. 2020.

MORAES, R.; BARTELMEBS, R. C. Análise Textual Discursiva: elementos introdutórios. In: THUM, C. (org.). Metodologias de Pesquisa em Educação: Horizontes metodológicos. Coleção Cadernos Pedagógicos da EaD, vol. 19. Rio Grande: Editora da FURG, 2013. p. 29 45 .

MORAES, R.; GALIAZZI, M. do C. Análise Textual Discursiva. Ijuí: Editora Unijuí, 2007.

MORETTI, F. A.; HUBNER, M. M. C. O estresse e a máquina de moer alunos do ensino superior: vamos repensar nossa política educacional?. Revista Psicopedagogia, São Paulo, v. 34, n. 105, p. 258-267, Julho. 2017. Disponível em:

$<$ http://pepsic.bvsalud.org/scielo.php?script=sci_arttext\&pid=S0103-

$84862017000300003 \& \operatorname{lng}=$ pt\&nrm=iso>. Acesso em: out. 2020.

PIAGET, J. Abstração reflexionante: relações lógico-aritméticas e ordem das relações espaciais. Porto Alegre: Artes Médicas, 1995.

SCHMITZ, T. Escrever.... A força de (re)criar o vivido. Revista Educação por Escrito, Porto Alegre, v. 1, n. 2, p. 144-147, dez. 2010.

SOUSA, R. S. de; GALIAZZI, M. do C. O jogo da compreensão na análise textual discursiva em pesquisas na educação em ciências: revisitando quebra-cabeças e mosaicos. Ciência e Educação, Bauru, v. 24, n. 3, p. 799-814, jul./set. 2018.

YUVAL, H. Homo Deus: Uma breve história do amanhã. São Paulo: Companhia das Letras, 2015.

Recebido em: 21 de outubro de 2020.

Aceito em: 12 de novembro de 2020. 